\title{
The Pathway from Smartness to Sustainability: Exploring the Transmission Mechanisms
}

\author{
José F. Perles-Ribes ${ }^{(\triangle)}$ (D) and Josep A. Ivars-Baidal (D) \\ Universidad de Alicante, 03690 San Vicente del Raspeig, Spain \\ \{jose.perles, josep.ivars\}@ua.es
}

\begin{abstract}
Smartness and sustainability have many points in common. Recent literature suggests that smartness would be a possibility to achieve the desired sustainability of tourist destinations. This article reviews the theoretical mechanisms that link both concepts and analyses their importance for a set of smart cities an destinations in Spain.
\end{abstract}

Keywords: Smartness $\cdot$ Sustainability $\cdot$ Theoretical mechanisms

\section{Introduction}

Among the many definitions that exist of smart cities, Caragliu et al. [5]. Consider that "a city is smart when investments in human and social capital and traditional and modern (ICT) communication infrastructure fuel sustainable economic growth and a high quality of life, with a wise management of natural resources, through participatory governance". Their adaptation to tourist destinations as "a knowledge-based destination, where information and communication technologies are used to provide a technological platform on which information and knowledge relating to tourism activities could be instantly exchanged" [6] would integrate the components to make the concept of sustainable tourism more operational.

The intensive use of technology involved in the implementation of a smart tourist destination allows the continuous measurement of aspects related to sustainability that, in the absence of this technology, are difficult or impossible to measure and manage [13]. Following this idea, Perles and Ivars [4] examine the existing links between both concepts and propose the theoretical transmission mechanisms operating in this context. The aim of this article is to empirically explore the importance of the proposed mechanisms to facilitate the optimization of the investments leading to sustainability.

\section{The Theoretical Pathway from Smartness to Sustainability}

The theoretical model (see Fig. 1) establishes the transmission mechanisms from smartness to sustainability for both smart cities and destinations. According to this framework, technology applied in smart destinations allows improvements in key aspects of planning and management. These improvements translate into a more efficient use of resources, costs saving and access to funds to invest in alternative and more 
sustainable uses. Technology also facilitates better governance processes and increases transparency, which facilitates a real commitment to the sustainable management of destinations. Finally, technology applied to marketing and open data policy facilitates the customization of tourism services and the strengthening of innovative dynamics that enhance the competitiveness of the tourism destination.

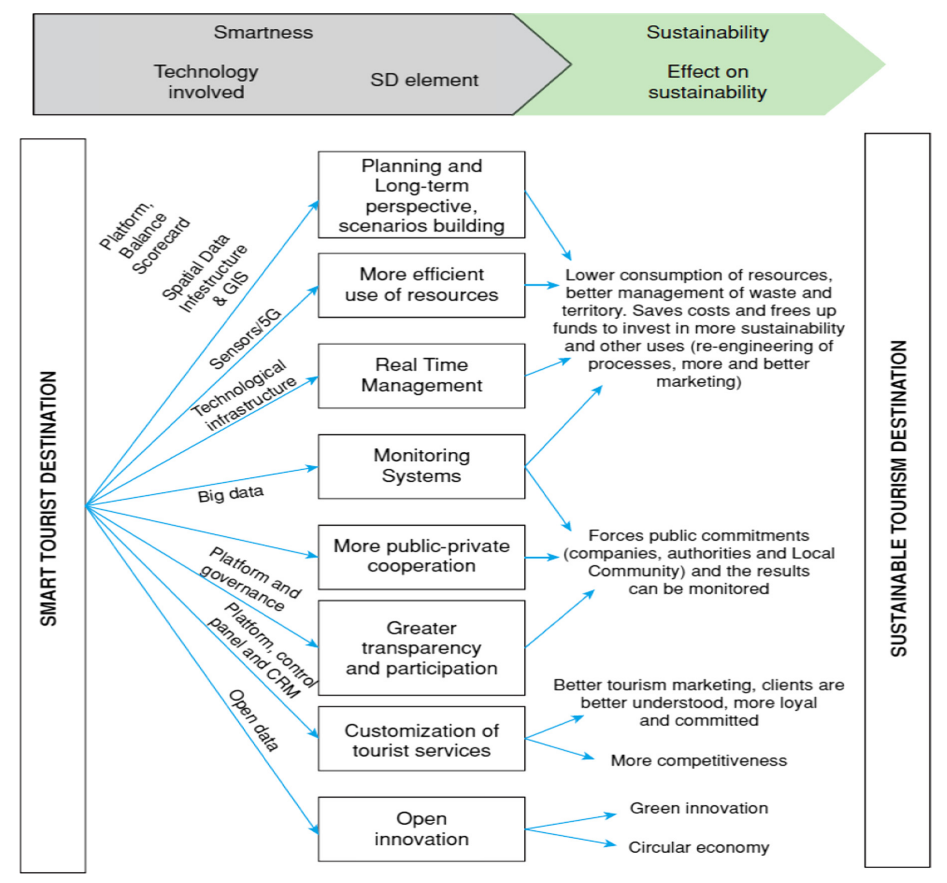

Fig. 1. Theoretical channels from smartness to sustainability (Source: Perles and Ivars [4])

\section{Methodology and Data}

In order to assess the relevance of the channels proposed in the model, primary data has been collected through an online survey addressed to managers leading smart cities and destinations initiatives in Spain. The questionnaire was developed within the framework of the research project "Analysis of planning processes applied to intelligent cities and tourist destinations. Balances and methodological proposal for tourist areas" (CSO2017-82592-R) financed by the Ministry of Science and Technology within the National Plan for R+D+i.

After a review of the literature, the items for each mechanism were formulated and a pretest was carried out to initially observe the understanding of a small sample of managers from the Valencian region.

Then, the questionnaire was sent to managers of Spanish smart cities and destinations initiatives, considering that these initiatives are developed in different departments of the local administration. After sending an invitation and several reminders, 
46 valid questionnaires were collected. In some cases, two questionnaires from the same city were received, while in others only one responsible manager answered. Smart cities initiatives include important regional or provincial capitals such as Madrid, Barcelona, Palma de Mallorca or Santa Cruz de Tenerife. The tourist destinations projects include Benidorm, Marbella, Córdoba or Toledo, among others. The sample is representative of those destinations that are at a more advanced stage of development in their conversion process towards a smart city or destination.

The variables analysed are related to the theoretical transmission mechanisms of Fig. 1. A set of items related with the question "the smart actions in your city/ destination have had a positive impact on..." valued in 7 point Likert scale with values ranging from 0 (strongly disagree) to 7 (strongly agree), 4 (neutral value) and 5 the score that implies agreement. These variables are studied for both, the smart cities and destinations case. The methodology of analysis is the exploratory data analysis.

\section{Results}

Table 1 shows the comparative results for smart cities and destinations (median and interquartile range results). Values are ordered from highest to lowest for smart destinations. In general, both managers of destinations and smart cities initiatives (median 6) consider that smart projects have improved the sustainability of the city or destination. Both medians are above the cut-off value of 5 (agree). Conversely, there is only one item that does not reach the cut-off value of 5 in the case of smart cities managers: reduction of tourist congestion.

Regarding the transmission mechanisms themselves, results show that the improvement of the management transparency is clearly perceived as the most relevant element. This item presents the highest median value and the lowest dispersion among smart destinations managers. Smaller improvements are perceived on the reduction of noise pollution, air quality, climate change mitigation, security levels, social inclusion, rationalization of public expenditure and reduction of tourist congestion. This could be attributed to the greater remoteness of these services from tourist destination managers and their difficulties to control them, as they are outsourced services in most destinations.

Regarding real time management and monitoring systems of cities/destinations, results reflect the practical difficulties of its implementation, both for tourist destinations and smart cities. Thus, the monitoring and control of public policies are ranked at the bottom of the list with the management of traffic in the destinations. 
Table 1. Empirical values for the theoretical transmission mechanisms.

\begin{tabular}{|c|c|c|c|c|}
\hline \multirow[t]{3}{*}{ Item (values 1 strongly disagree -7 strongly agree) } & \multicolumn{2}{|l|}{$\mathrm{n}=14$} & \multicolumn{2}{|l|}{$\mathrm{n}=23$} \\
\hline & \multicolumn{2}{|c|}{$\begin{array}{l}\text { Smart } \\
\text { destinations }\end{array}$} & \multicolumn{2}{|c|}{ Smart cities } \\
\hline & Median & IQR & Median & IQR \\
\hline Management transparency & 7 & 1.75 & 6 & 2 \\
\hline Image of the city & 6.5 & 1.75 & 6 & 2 \\
\hline Collaboration with universities and research centres & 6 & 1 & 6 & 3 \\
\hline Energy efficiency & 6 & 1 & 6 & 2 \\
\hline Encouraging entrepreneurship & 6 & 1.5 & 6 & 3 \\
\hline Promoting sustainable mobility & 6 & 1.75 & 6 & 2 \\
\hline Citizen-oriented public services & 6 & 1.75 & 6 & 2 \\
\hline Generating a more competitive city & 6 & 1.75 & 5 & 3 \\
\hline A more sustainable city & 6 & 2 & 6 & 2 \\
\hline Universal accessibility for disabled people & 6 & 2 & 6 & 2.5 \\
\hline Waste management & 6 & 2 & 6 & 2.5 \\
\hline Generating a more innovative city & 6 & 2 & 6 & 3 \\
\hline Public-private partnership & 6 & 2 & 5 & 2 \\
\hline Sustainable public transport & 6 & 2.75 & 6 & 2 \\
\hline Interdepartmental collaboration & 6 & 2.75 & 6 & 3 \\
\hline Protection of biodiversity and urban ecosystems & 6 & 2.75 & 5 & 2.5 \\
\hline Water cycle management & 6 & 3 & 6 & 2 \\
\hline Quality of urban public spaces & 5.5 & 2 & 6 & 3 \\
\hline Citizen participation & 5.5 & 2 & 6 & 1.5 \\
\hline Business attractiveness & 5.5 & 2 & 5 & 3 \\
\hline Traffic management & 5.5 & 2.75 & 6 & 2 \\
\hline Monitoring and control of public policies & 5.5 & 2.75 & 5 & 2.5 \\
\hline Reduction of noise pollution & 5 & 1 & 5 & 2 \\
\hline Air quality & 5 & 2 & 6 & 2.5 \\
\hline Climate change mitigation & 5 & 2 & 5 & 1.5 \\
\hline Security levels & 5 & 2 & 5 & 2 \\
\hline Greater social inclusion & 5 & 2 & 5 & 2 \\
\hline Rationalization of public expenditure & 5 & 2 & 5 & 3 \\
\hline Reduction of tourist congestion & 5 & 2 & 4 & 3 \\
\hline
\end{tabular}

Authors own elaboration. 
In relation to transparency, participation and public-private collaboration, managers perceive positively the impact that smart projects have on the general management of destinations. They also consider as favourable the relationship of these managers with the academic field from which some of these smart initiatives emerged. This improvement in transparency is accompanied with improvements in other aspects such as interdepartmental collaboration, citizen participation and public-private partnership. The absence of the later has always been highlighted as a burden on improving the sustainability of destinations.

Regarding customization of tourism services and innovation, managers recognise the potential of smart projects to generate innovative cities, improve their image, promote entrepreneurship and generate citizens and tourists-oriented services. All these improvements lead to a more competitive city. Therefore, there is a favourable agreement towards this statement among both destination (median 6) and smart cities managers (median 5).

Finally, regarding the accessibility side of smart destinations, managers also perceive the potential role of smart projects to improve these relevant aspects. However, the possibility of improving universal accessibility for disabled people is better perceived than the improvements towards a greater social inclusion.

\section{Conclusions}

Tourism literature points out the existence of a relationship between smartness and sustainability. Literature has also shed light on the theoretical mechanisms of transmission that operate in this context. On this theoretical basis, this article has tried to assess the importance of the mechanisms proposed by Perles and Ivars [4] in a relevant set of Spanish smart destinations and cities. Two preliminary conclusions have been obtained. First, the results point out that the implementation of smart projects promotes incremental improvements in the sustainability of cities and destinations. Second, the channels and mechanisms proposed by the pre-existing literature seem to be appropriate, being most of them favourably perceived by destinations managers.

Future research based on the evaluation of real data on the evolution of destinations and cities may confirm or refute the results obtained in this paper through surveys addressed to cities and destination managers.

\section{References}

1. Ahvenniemi H, Huovila A, Pinto-Seppä I, Airaksinen M (2017) What are the differences between sustainable and smart cities? Cities 60(A):234-245

2. Ali A, Frew AJ (2014) Technology innovation and applications in sustainable destination development. Inf Technol Tour 14(4):265-290

3. Perles JF, Ramón AB (2018) Obliquity in tourism economics: smart and sustainable tourist destinations. e-Rev Tour Res (eRTR) 16(1):45-55

4. Perles JF, Ivars JA (2018) Smart sustainability: a new perspective in the sustainable tourism debate. Investigaciones Regionales J Reg Res 42:151-170 
5. Caragliu A, Del Bo C, Nijkamp P (2011) Smart cities in Europe. J Urban Technol. https://doi. org/10.1080/10630732.2011.601117

6. Jovicic D (2016) Key issues in the conceptualization of tourism destinations. Tour Geogr 18 (4):445-457

Open Access This chapter is licensed under the terms of the Creative Commons Attribution 4.0 International License (http://creativecommons.org/licenses/by/4.0/), which permits use, sharing, adaptation, distribution and reproduction in any medium or format, as long as you give appropriate credit to the original author(s) and the source, provide a link to the Creative Commons license and indicate if changes were made.

The images or other third party material in this chapter are included in the chapter's Creative Commons license, unless indicated otherwise in a credit line to the material. If material is not included in the chapter's Creative Commons license and your intended use is not permitted by statutory regulation or exceeds the permitted use, you will need to obtain permission directly from the copyright holder. 